\title{
Archaeological reconnaissance of the Late Pleistocene Red Sea coast in the Danakil
}

\author{
Yonatan Sahle ${ }^{1} \&$ Amanuel Beyin ${ }^{2}$
}

\section{Introduction}

The paucity of archaeological evidence from the northern Afar Rift and Red Sea littoral remains a major hindrance to testing the hypothesised Out-of-Africa dispersal of early humans via the 'Southern Route'-across the Bab al-Mandeb into Arabia and beyond. Encouraged by renewed geological studies (e.g. Atnafu et al. 2015), and recent archaeological discoveries (e.g. Walter et al. 2000; Beyin 2013), we initiated a pioneering exploration along the ancient Red Sea coast in the Danakil Depression (Figure 1a-c). The most conspicuous geomorphological features here constitute terraces of reef carbonates and associated marine deposits, formed when the depression was covered by the open Red Sea during the Middle to Late Pleistocene. Initial results of our exploration promise contexts in which the distribution and cultural/behavioural adaptation of early humans during the Out-of-Africa event can be closely investigated.

\section{Theoretical and regional background}

Adaptation to coastal environments and the exploitation of marine resources are considered crucial for the survival of early humans and their successful Out-of-Africa expansion during the early Late Pleistocene (126000 to approximately 60000 years ago; Marean 2014). The scarcity of Palaeolithic coastal sites in north-eastern Africa confounds the assessment of models of ecological and technological/behavioural adaptations during the dispersal (e.g. Mellars 2006; Shea \& Sisk 2010).

The Danakil Depression preserves successive marine deposits of Middle and Late Pleistocene age, indicating that the basin was once connected with the Red Sea. Bannert et al. (1971) and Bonatti et al. (1971) suggest that multiple phases of alternation between restricted and open marine conditions characterised the region $230000-24000$ years ago. Desert ecosystems and volcanic flows represent much of the general landscape today. The basin floor is dotted with closed lakes that act as natural reservoirs. That this same region hosted a marine niche in the past makes it a particularly unique setting for assessing the extent to which aquatic environments may have contributed to the survival and successful

1 DFG Center for Advanced Studies, University of Tübingen, 72070 Tübingen, Germany (Email: yonatan.sable@ ifu.uni-tuebingen.de)

2 Department of Anthropology, University of Louisville, Louisville, KY 40292, USA (Email: amanuel.beyin@ louisville.edu) 


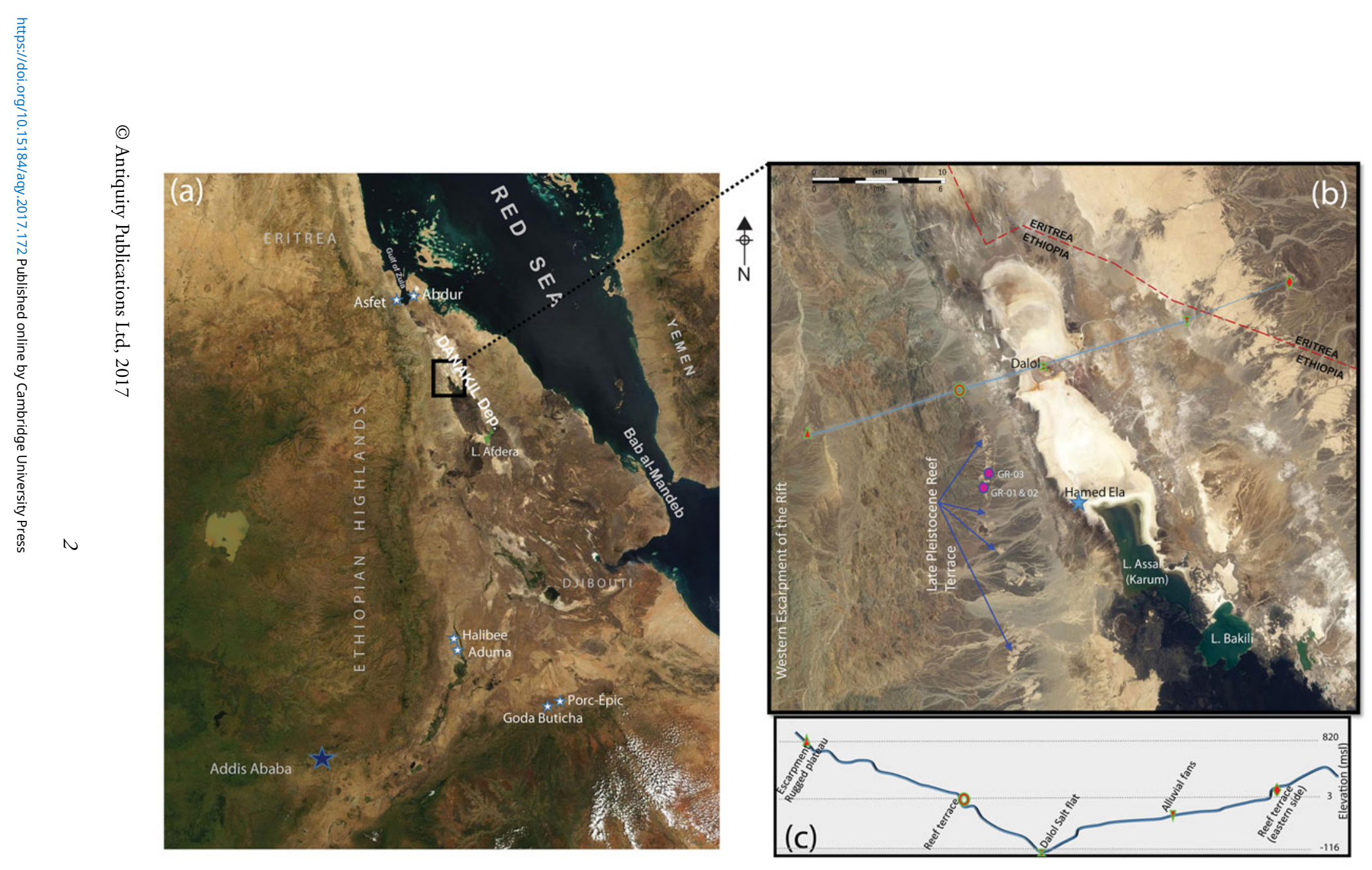

Figure 1. a) Location of the study area relative to the Danakil, the southern Red Sea coast, Bab al-Mandeb and major Late Pleistocene sites with human remains; b) a close-up of the major survey area (GR=Girawi'en); c) topographic profile along the line indicated in ' $b$ '. 
(a)

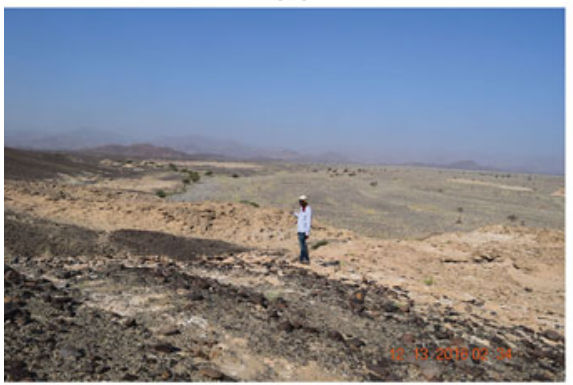

(b)

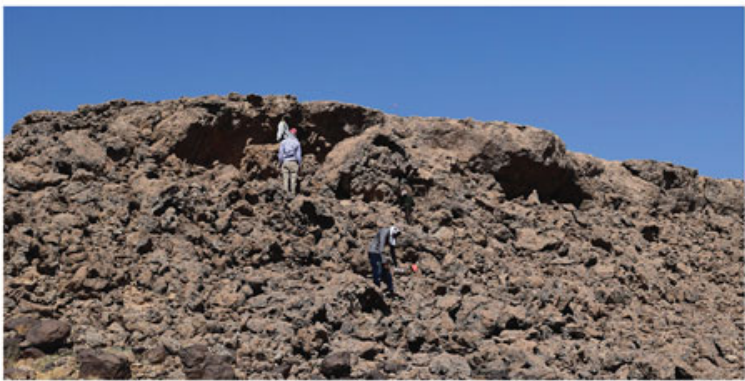

(d)

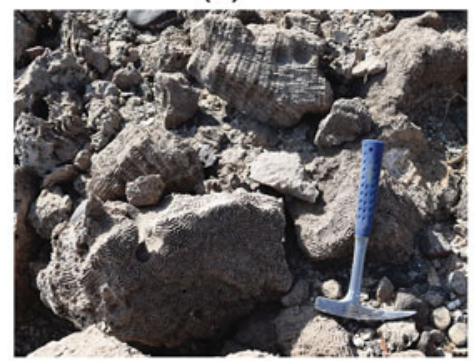

(e)

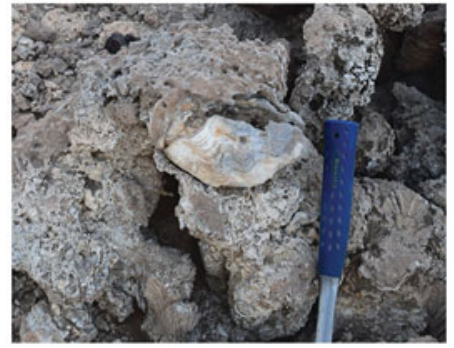

Figure 2. The fringing reef exposures in the northern Danakil: a) roughly mark the early Late Pleistocene sea level; b) form a resistant terrace; $c-e$ ) contain reef skeletons and various types of shells.

dispersal of our lineage. Attempts are being made to refine these age constraints (e.g. Atnafu et al. 2015), which promise superior chronological baselines for resolving outstanding questions surrounding the contexts for the Out-of-Africa dispersal.

\section{Methods and target deposits}

Our reconnaissance survey focused primarily on the western side of the Danakil Depression, including the foothills of the western margin of the Rift between Lakes Afdera and Assale (Figure 1a \& b). The eastern side was avoided for security reasons. The fringing carbonates and coral reefs that trend north-north-west to south-south-east, as well as adjoining fluvial sediments, were particularly closely explored. Conspicuous and laterally extensive, the fringing reefs in this area serve as marker-beds defining the ancient sub-sealevel landscape. Our survey employed a telescoping approach — a hierarchical inventory of target features identified on satellite imagery, followed by ground-truth information acquired along vehicle and foot transects. Documentation of sites included local names, GPS coordinates, detailed photographs (with accompanying catalogues) and descriptive field observation notes. Representative artefacts and reef samples were collected, where it was deemed necessary. 
(a)

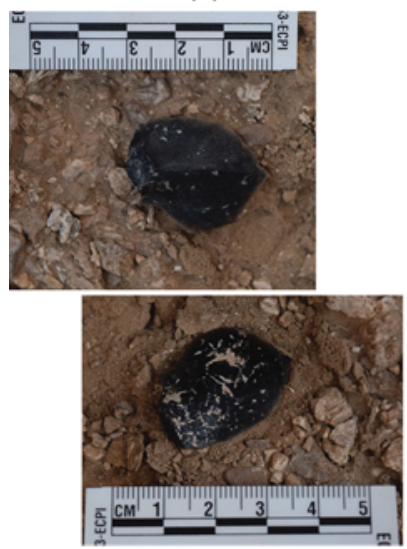

(d) (b)

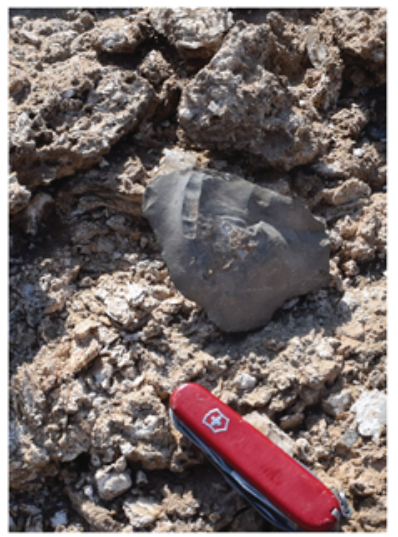

(c)

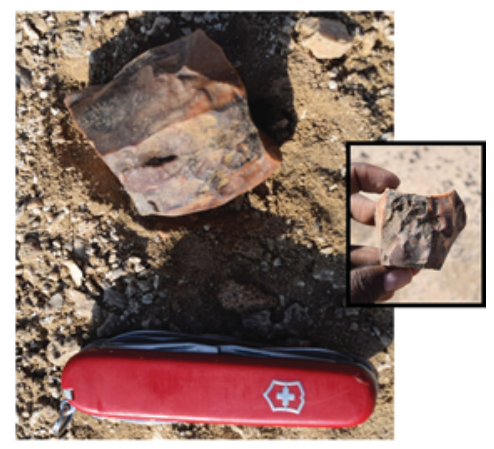

(e)

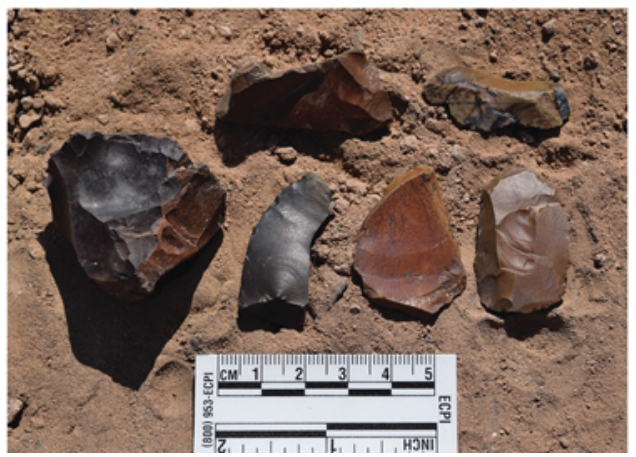

Figure 3. Some of the artefacts from the Girawi'en localities: a) obsidian flake with adherent carbonate matrix; b) coneshaped single platform core on basalt with adherent carbonate matrix; $c$ ) convergent flake from a Nubian core on patinated chert; d) chert prismatic blade core; e) miscellaneous flakes and a single-platform cone-shaped core, all made on siliceous raw material.

\section{Results}

Our reconnaissance started with a positive identification of marine reef terraces that appear to belong to the Last Interglacial sea-level highstand, roughly equivalent in age to the $\sim 125$ 000-year-old Abdur Reef Limestone (Walter et al. 2000). Aligned along the axis of the Danakil Depression, this exposure features a conspicuous reef terrace three to eight metres in thickness (Figure 2a-b). In most of the surveyed localities, it is overlain by alluvial deposits, including lava gravels that are typical of the adjoining western margins of the Rift. Another reef terrace of Middle Pleistocene age is visible at a much lower elevation, but this was not our primary target. The upper reef outcrop exists in the form of intact ledges and rolling blocks (collapsing from the original reef terrace) rich in marine shell and coral contents (Figure 2c-e). In general, lithic artefacts are rare in and near the marine deposits. The indurated nature of the reef carbonates discourages active and quick erosion of artefacts

(C) Antiquity Publications Ltd, 2017 
that may still be embedded within the reef limestone, as is the case at Abdur (Walter $e$ e al. 2000: fig. 2). Ascertaining the full archaeological potential of these deposits will, therefore, require rigorous surveys covering larger areas.

One of our surveyed localities, namely Girawi'en, has yielded a modest scatter of freshly eroded artefacts within the reef exposure north-west of Hamed Ela (Figures 1b \& 3a-e). Here, a steep reef terrace emerges from an escarpment perching on a vast floodplain that stretches over several kilometres towards Lake Assale. Artefacts were recovered from the surface of, or just under, the reef deposits. Few artefacts retain adherent carbonate matrix, hinting at the possibility of recent erosion from within the reef carbonates (Figure 3a-b). Most of the artefacts can be described as flakes, with two prismatic cores and a convergent Levallois flake. Techno-typologically, these artefacts exhibit characteristics of the African Middle Stone Age tradition. More confident attribution and meaningful interpretation, however, require larger, systematically excavated assemblages.

Finally, our survey explored the beach sand sediments north-west of Lake Afdera (Figure 1a-b). These exposures appear to be part of the latest marine retreat as well as high lake stand events in the area, in that as with the ancient Red Sea, Lake Afdera seems to have experienced fluctuations in its levels. These deposits contain sparsely scattered surface artefacts (and fewer fossils), reminiscent of the terminal Pleistocene/early Holocene of the wider region.

In summary, our reconnaissance has successfully assessed the archaeological potential of the early Late Pleistocene reef outcrops in the Danakil Depression. Specifically, we have documented and collected several isolated and clustered artefacts. These results encourage continued archaeological research in the region and promise to contribute towards addressing unresolved issues about early human dispersal(s) Out of Africa.

\section{Acknowledgements}

Research was conducted under permission from the Authority for Research and Conservation of Cultural Heritage of Ethiopia. We are grateful to kind support from D. Dagne, T. Leta and several other colleagues in Addis Ababa and the Afar region. Travel funding for A.B. was provided by the Department of Anthropology, University of Louisville.

\section{References}

Atnafu, B., T. Kidane, A. Foubert,

D. Jaramillo-Vogel, J.-C. Schaegis \&

J.-P. HenRiet. 2015. Reading history from Afar.

Eos: Earth Planet Science News 96.

https://doi.org/10.1029/2015EO022789

BANNERT, D., J. BRINCKMANN, R. JORDAN,

M. Kürsten, G. Ochse, H. Ries \& F. Schmid.

1971. Beiträge zur Geologie der Danakil-Senke

(NE-Äthiopien). Beihefte zum Geologischen Jahrbuch

116: 1-199.
Beyin, A. 2013. A surface Middle Stone Age assemblage from the Red Sea coast of Eritrea: implications for Upper Pleistocene human dispersals Out of Africa. Quaternary International 300: 195-212. https://doi.org/10.1016/j.quaint.2013.02.015

Bonatti, E., C. Emiliani, G. Ostlund \& H. Rydell. 1971. Final desiccation of the Afar Rift, Ethiopia. Science 172: 468-69. https://doi.org/10.1126/science.172.3982.468

Marean, C. 2014. The origins and significance of coastal resource use in Africa and Western Eurasia. Journal of Human Evolution 77: 17-40. https://doi.org/10.1016/j.jhevol.2014.02.025 
Mellars, P.A. 2006. Why did modern human populations disperse from Africa $c a$. 60,000 years ago? A new model. Proceedings of the National Academy of Sciences of the USA 103: 9381-86. https://doi.org/10.1073/pnas.0510792103

Shea, J.J. \& M.L. Sisk. 2010. Complex projectile technology and Homo sapiens dispersal into Western Eurasia. Paleoanthropology 2010: 100-22.
Walter, R.C., R.T. Buffler, J.H. Bruggemann, M.M.M. Guillaume, S.M. Berhe, B. Negassi, Y. Libsekal, H. Cheng, R.L. Edwards, R. von Cosel, D. Néraudeau \& M. Gagnon. 2000. Early human occupation of the Red Sea coast of Eritrea during the last interglacial. Nature 405: 65-69. https://doi.org/10.1038/35011048 